\title{
Managing Highly Innovative Projects: The Influence of Design Characteristics on Project Valuation
}

\author{
S. Sinan Erzurumlu \\ Technology, Operations and Information Management Division \\ Babson College \\ 231 Forest $\mathrm{St}$ \\ Babson Park, 02457, USA \\ serzurumlu@babson.edu \\ Jane Davies \\ Judge Business School \\ University of Cambridge \\ Trumpington Street \\ Cambridge, UK CB2 1AG \\ j.davies@jbs.cam.ac.uk \\ Nitin Joglekar \\ School of Management \\ Boston University \\ 595 Commonwealth Avenue \\ Boston, MA 02215, USA \\ joglekar@bu.edu
}


Keywords: Innovation Management; Risk Management; Operational Hedging; Resource-based View; Operations Design; Clean Technology; Technology Entrepreneurship; Government Funding; ARPA-E

\begin{abstract}
The climate change debate and economic recovery strategies in various industries demand highly innovative projects featuring stretched performance goals for developing clean technology. These projects face multiple sources of uncertainty in high risk situations, and require specialized knowhow and longer periods for revenue growth than their counterparts in other industries. We use empirical data from 207 clean technology projects funded by the U.S. Advanced Research Projects Agency-Energy (ARPA-E) to conduct a comparative study of how operations design can hedge risk and enhance project valuation in technology development and deployment stages. We find that deployment feasibility is significantly and positively related to project valuation. On the other hand, stretched technical performance goals, development feasibility and market growth targets are associated with lower valuation. We also find some significant differences for these results across institution types: mature firms, start-ups, universities, and research centers. We examine the risk profile of these projects by technology and institution type, and discuss the managerial and policy implications for these findings.
\end{abstract}




\section{BIOGRAPHIES}

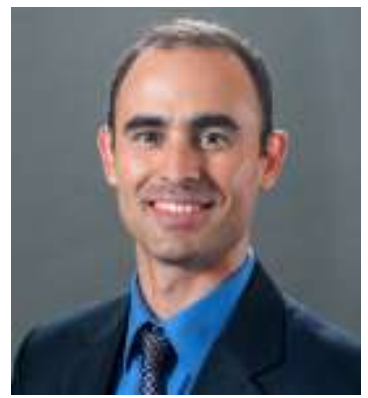

S. Sinan Erzurumlu was educated at Bogazici University and later received his doctoral degree in supply chain and operations management at the University of Texas at Austin. His work experience includes operations consulting at technology organizations. At present, he is on the faculty at Technology, Operations and Information Management Division, Babson College. He is also engaged as the vice president in the Technology Management Section at INFORMS. His research interests include technology and innovation management, technology commercialization, entrepreneurial operations and sustainability. He is a member of DSI, POMS, M\&SOM, and AoM.

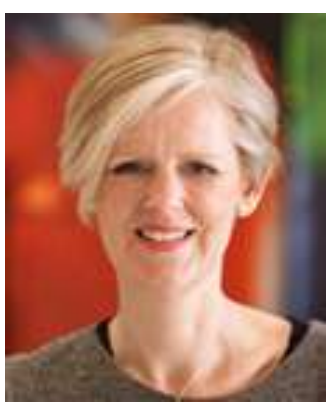

Jane Davies was educated at the University of Brighton and the London School of Economics, she later studied for her doctorate at Boston University School of Management. Prior to her academic career, she spent ten years consulting with companies in the finance, telecoms and public sectors on operational and technology change projects. At present she is on the faculty at the University of Cambridge Judge Business School. Her current research interests include assessing the value of operations to organizations and the role of operations in entrepreneurial ventures.

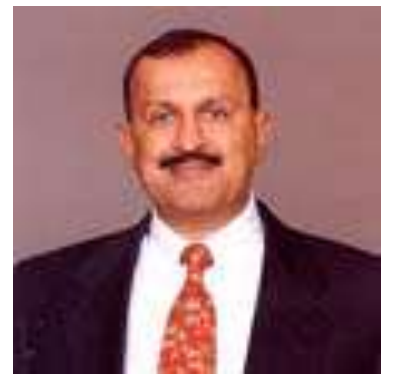

Nitin R. Joglekar was educated at IIT Kharagpur and at MIT. He received a doctoral degree in management science. His work experience includes stints in the energy and IT industries. At present he is on the faculty at Boston University's School of Management. His current research interests are product and service development, technology commercialization and entrepreneurial operations. He is a member of IEEE. 


\section{INTRODUCTION}

Emphasis on increasing energy security and reducing carbon emissions has seen a heightened interest in the development of highly innovative technologies in the U.S. that reduce reliance on energy imports, cut energy-related greenhouse gas emissions, and improve efficiency across the energy spectrum [44]. On the other hand, the anticipated innovations typically require long development times (5-15 years), need in-situ experimentation for scaling up production, and must be designed for 30 plus year life span. Further, commercialization is difficult, in particular, for cash-starved start-up managers who have to first verify their prospects [22]. Hence, the timing of the cash flows and the risk profile of highly innovative projects make them unattractive to conventional funding sources, such as debt financing, venture capital (VC) funds and corporate investors [19]. According to World Bank, clean technology industry could not gain anticipated momentum because of this financing dilemma faced by clean technology organizations working on high risk, high reward technologies.

In this study we focus on highly innovative projects with stretched development goals that were expected to deliver significant technical performance improvements over existing technologies. As unpredictable as they may be, these projects could generate high rewards with respect to incumbent technologies, and eventually be adopted by the industry, establish standalone businesses, and stimulate economic growth. In particular, we examined the transformational technology projects funded by Advanced Research Project Agency-Energy (ARPA-E) of US Department of Energy (DoE) as highly innovative technologies. For example, Foro Energy, which had been funded over $\$ 9 \mathrm{M}$ by ARPA-E in 2008, was developing a breakthrough thermal energy technology that would break and weaken ultra-hard crystalline rock for efficient cutting that might increase drilling rates up to " 10 -fold" relative to existing 
technologies. This development would transform the geothermal industry as it would expedite drilling speeds, expand drilling areas, and reduce costs. Another applicant, Eaton Corporation, was funded for its battery management technology to optimize fuel economy of commercial hybrid vehicles. Coupled with battery models, Eaton's technology would remove barriers to electric vehicle ownership and make them cost-competitive with non-hybrid vehicles.

Understanding emerging themes and betting on the highly innovative projects have been a constant challenge for the investors (e.g., failures in clean technology, [38]) owing to the scope of the innovations, risks in the underlying scientific processes, the scale of funding, and the requirements to link emergent technologies into the existing infrastructure [22]. Thus, no matter how innovative and significant may be the idea, risk minimization is essential to an organization's potential for receiving funds. In this paper, we examine whether any operational conceptualization of a highly innovative technology project affect project valuation. We posit that operations design (the ability to configure resources and processes, e.g., scale, production, resource planning, and so on) and the institution types (e.g., start-ups versus universities that provide unique contexts for risk taking) might affect project valuation and financing for the organization. The operational risk mitigation levers might play a distinctive role on project valuation by demonstrating the capability to mitigate technology performance, development, deployment, and market growth risks. In other words, operations design, in this context, is considered as a hedging tool to manage the uncertainty of a highly innovative, high risk/high reward project.

The shared issue across these types of innovation projects is if there is systematic variation in the manner in which the management of these projects is valued either by institution type or by technology type. Accordingly, we set up a comparative study of 207 projects funded by ARPA- 
E and build a theoretical framework to understand the relationship between risk mitigation levers and project valuation. We further determine if this relationship is moderated by the institution and technology types. To the best of our knowledge, there have been no studies that test the nexus between the operations design in response to project uncertainty, and the valuation of stretched technology ventures in a high risk/high reward setting.

\section{THEORETICAL BACKGROUND}

\section{A. Stretched Innovation Goals}

Setting stretched goals for highly innovative clean technology projects with significant returns require a long time horizon for return on investment and a large capital outlay for what is highly unpredictable development, adoption and growth [27], [40]. Similar challenges has been recognized in the pharmaceutical industry in which development timeline is extending with high costs and unpredictability and the regulators are becoming more risk-averse [41]. Also, operational and financial uncertainties exacerbate information gap between the owners of the technology and resource providers (i.e., financiers). This is particularly the case in the start-up context, where uncertainty associated with development and stretching is high [13], and this phase of life cycle with high risk before the start-up growth has been described as the "valley of death" [32].

Consequently, the information gap forces many, if not most, highly innovative and high risk projects to seek alternative funding resources to overcome credit scrutiny [33], e.g., from government and other institutions [15]. Governments have interest in offering subsidies because not only social returns may exceed private returns, but this may also signal the value of the project to private investors [33]. Hence, support from governments can substantially influence the rate and direction of technological advances, but receives its share of criticism regarding the 
risky nature of these projects. For instance, in clean technology there has been debate on how DoE should minimize potential risks in funding clean technology projects [39]. Further, in evaluating a technology project, private investors like VCs employ similar criteria to what we have considered in our study, e.g., the promise of the technology performance, and the size of the potential market [34]. Thus, our study is relevant to different types of creditors because we address the information problems that preclude investors.

\section{B. Operations Design}

The acquisition of resources from investors and the assurance of their effective and efficient use are critical to any organization's survival and growth [28]. According to the resource-based view (RBV) of the organization, the organizational ability to grow is driven by internal resources, which are distinguished between human, organizational and financial resources; and the organization can maintain competitive advantage from obtaining resources and capabilities (such as management skills, processes, knowledge) that are rare, valuable, inimitable and not substitutable [7]. Relevant to deal with the realities of changing conditions, recent research on RBV has advocated for a more dynamic examination of the black box of resources -how they are assembled and built over time [26].

Akin to dynamic RBV, the goal of operations design is to maximize net organizational value by acquiring resources and configuring processes such that the resulting capabilities are always aligned with competitive positioning [43], [55]. Operations design manages trade-offs related to structural investments, e.g., capacity, facility size and location, vertical integration, product and process technology, and infrastructural decisions, e.g., production planning and control, human resource management, organizational design, quality management practices, as well as investments in capability building to mitigate value degradation due to uncertainty [24], [46]. 
Hence, managing project characteristics through risk mitigating operations, rather than focusing on financial goals, is deemed one route to improve performance and perform feasible activities key to the long-term growth [46].

\section{Risk Management and Operational Hedging}

All projects are exposed to uncertainty, some of which are technology-specific and organization-specific (e.g., performance and feasibility uncertainty), whereas the rest are inherent and common to all organizations in the economy such as demand, market and growth uncertainties. Risk management is concerned with planning and decision-making to quantify these uncertainties and deal with risk occurrence. Corporate finance literature identifies a variety of financial hedging strategies to manage risks with financial tools, e.g., options, derivatives, and conservative financial policies [51]. However, financial management tools may not be appropriate for a project due to resource configuration, making it difficult to control through the use of financial contracts [20], [23].

Given that organizations in need of unique characteristics for highly innovative technologies have to bear significant operational and financial risks, it becomes hard to assess their risk profile [9], [10]. In the operations management literature empirical investigations show that organizations could indeed manage risks using operations, i.e., through operational hedging [2]. These operational activities like flexibility, capacity, postponement, are similar to real options. Real options are "opportunities to delay and adjust investments and operating decisions over time in response to resolution of uncertainty" [50]. Thus, real options in our context are referred to as operational hedging mechanisms.

In the operations management literature operational hedging is defined as the organization's ability to anticipate and respond to uncertainty and change in development and market conditions 
flexibly by means of structuring of resources and processes with product, production and supply chain options [29], [54]. For instance, an institution that lacks financial resources, more so with start-ups, can manage supply uncertainty to accommodate future growth with structural and production volume decisions [47]. Operations design, which is integral to operational hedging, contributes to the assessment of project risk profile through structuring of operational activities. Hence, the extent to which operational activities are completed or the initiation of marketing efforts is critical to financing for a fund-seeking organization [21]. In this paper we examine that managers of highly innovative and risky projects could use operations design to improve project valuation by displaying proof of fit between the demand of the project and the risk mitigation levers in terms of performance, growth and feasibility.

\section{THEORY AND HYPOTHESES}

In this study, we consider highly innovative prospective technologies that pose high degrees of risk in technology development and deployment. Whereas the development stage involves basic and applied science, prototype, demos and laboratory testing, the deployment stage is concerned with production at scale, market diffusion, use and commercialization. We develop a comprehensive framework of risk mitigation levers and theory for project valuation, related to the RBV [26], and operations design and hedging [24], [55]. To determine the extent that operations design will determine risk mitigation levers, which in turn influence project valuation, a closer examination of key characteristics is in order.

Past studies in product development literature have shown that a new product's success depends critically on its performance [31] and studied the content of the design (e.g., the complexity of each part, the number of parts) for performance [55]. In this research stream product architecture, which is the physical structure of design, determines the novelty, 
complexity, and functionality of the product design, and has implications beyond performance for marketing [52], for organizational design [42], and for the evolution of entire industries [6]. Product architecture of high complexity and novel technological requirements may result in inefficient product design, and thus, generate a higher risk of performance failure [36]. [48] show that technology novelty and project complexity contribute to project task uncertainty and are therefore associated with project execution outcomes.

Hence, we argue that technology performance that mitigates technological complexities and challenges will enhance project valuation, but the stretched performance goals (i.e., complexity, novelty and efficiency) may raise concerns about associated risks. For example, Phononic Devices in ARPA-E dataset, which was working on a novel method to convert waste heat into usable electric power, presented its current thermoelectric device design in its grant application in order to demonstrate efficiency and performance of its technology. To qualify for financing SolarBridge Technologies offered the details of its novel technique to generate solar energy efficiently relative to conventional methods, which would enable the company to operate with superior performance in the global solar industry. Then, we predict that

H1: Project valuation will be positively/negatively associated with targeted technology performance.

In addition to the content of technology design, another body of work in operations management looked into the impact of design and development practices for project success [1], [5]. The development process is a complex web of interactions and must determine the feasibility, efficiency and predictability of the technology [11]. A start-up might face higher risks about the costs and technical development due to limited resources [19], and start-ups with better access to resources are more likely to be innovative in development [14]. Large organizations 
with a prototype could demonstrate progress in the product development process by achieving technical and financial feasibility [31]. For example, in our ARPA-E dataset, MI-based REL Inc. was working on a conformable core gas tank to provide improved storage capacity in any natural gas vehicle. In its application the company demonstrated technical aspects of their development process in anticipation of higher funding. Therefore, we argue that

H2: Project valuation will be positively associated with the feasibility of technology development.

The main factors impacting project success, as identified in several empirical studies, include not only a unique superior technology, but also a strong market orientation [17], [30]. Structural investments on operations design, production and scale-up lead to distinctive capabilities and determine an organization's effectiveness in achieving desired position [24]. The winners from the large array of technologies build augmented and flexible use of systems and realistic massscale commercialization [22]. In particular, the adoption rate of clean technologies has relied on complementary technologies and industries and a feasible infrastructure to fulfil the customer's “job-to-be-done” [16]. For example, Bio Architecture Lab that was awarded funding by ARPA-E laid out plans for the development of distribution infrastructure in proof of commercial viability of biofuels. REL Inc. with a durable prototype for a conformable core gas tank further revealed its goal for feasible deployment by showing that its prototype could be easily scaled up with a cost effective plan. However, highly innovative projects pose significant risks in technology deployment--adoption and use [30]. Deployment feasibility, which emphasizes operational infrastructure, scale and growth, will be preferred since it mitigates long-term business and market risks, and increases project valuation. Thus, we expect that 
H3: Project valuation will be positively associated with the feasibility of technology deployment.

New technology projects are traditionally judged by market success and economic growth [57]. In our framework, ARPA-E projects were evaluated on their potential to generate long-term economic growth similar to the role of other innovative activities. [35] indicate that in the hightech manufacturing sector commercial success of new product development projects is primarily determined by market share. On one hand, the success of highly innovative projects depends on the potential for sustained market success, i.e., robust market growth. In our earlier example, Phononic Devices in search of funding provided proof for potential market growth by showing that electronics manufacturers could easily manufacture and integrate the device into their products. On the other hand, the growth targets might be deemed risky by investors due to their long time horizon for return on investment. Hence, we argue that

H4: Project valuation will be positively/negatively associated with targeted growth.

Managing high risk technology development and deployment projects bears critical challenges, and managerial issues have appropriately received considerable attention in the product development literature, mainly in rather large and mature organizations; see review by [31]. Nevertheless, the traditional measures in product development may no longer be applicable on large public sector development projects [49]. Start-ups endowed with unique characteristics regarding their asset structure and growth orientation are often restricted by debt and other financial considerations [9]. Specifically, the information gap between the financiers and the start-up is wider due to these characteristics and restrictions [22]. Since operations design will ultimately deal with specific demands from different organizations, we consider potential risks with respect to institution type (start-ups, mature firms, universities and non-profits, and research 
centers). We, in particular, design a comparative study and argue that the impact of risk mitigation levers will be moderated by institution type.

H5a: The impact of technology performance on project valuation will be mediated by i) mature firm, ii) start-up, iii) university and non-profit, and iv) research center.

H5b: The impact of feasibility of technology development on project valuation will be mediated by i) mature firm, ii) start-up, iii) university and non-profit, and iv) research center.

H5c: The impact of feasibility of technology deployment on project valuation will be mediated by i) mature firm, ii) start-up, iii) university and non-profit, and iv) research center. H5d: The impact of feasibility of targeted growth on project valuation will be mediated by i) mature firm, ii) start-up, iii) university and non-profit, and iv) research center.

The framework of our research model is shown in Fig. 1.

[INSERT FIGURE 1 HERE]

\section{RESEARCH METHOD}

\section{A. Data Set}

Our empirical work focuses on the funding of highly innovative clean technology projects by ARPA-E. These projects covered a broad spectrum of technology types: delivery of electrical power technology, energy storage, thermo-devices, electricity network, carbon capture, biofuels, and rare earth alternatives in technologies. Each project is awarded a different amount of funding based on the level of risk and their potential for adoption and growth. Since 2009 ARPA-E funded 207 projects, 108 projects from universities, non-profits and research centers, and 99 projects from start-ups and large corporations, ranging from a quarter of a million to $\$ 9$ million, for a total value of over $\$ 590$ million. Further, the projects accepted for funding were prescreened by the expert team of ARPA-E on the basis of national economic and social value 
generation [4]; therefore, this allows us to work with a group of highly scrutinized projects. Overall, ARPA-E projects provide a rich and validated dataset of highly innovative technologies with stretched goals to understand the role of operational risk mitigation levers on project valuation.

\section{B. Overall Research Approach}

Understanding the role of operational hedging on project value motivates this research. Our methodology focuses on the documentation of a range of risk mitigation levers affecting clean technology project valuation. We examine the specifications for 207 ARPA-E funded projects using content analysis to identify which operations design factors are utilized in high risk, high reward technology development and deployment. We analyze the information available in the public filing of statements for the ARPA-E funded projects and the project web sites using WordStat's content analysis tool. We then employ factor analysis to understand the underlying structures and relationships that exist among the operations design and risk mitigation activities used in these projects. We subsequently determine seven risk mitigation levers among the latent variables. We use these factors in order to produce an econometric model that explains the relationship between the risk mitigation levers, created by operations design and hedging, and the project valuation, in terms of funding amount. We further conduct a comparative study for highly innovative technology projects by considering different institutions and technology types.

\section{Statistical Method}

Testing our hypotheses requires the estimation of the risk mitigation levers that explain the project valuation. Based on the conceptual framework, a basic model for the valuation of project $i$ is specified as:

Project_Valuation $_{i}=\alpha_{0}+\alpha_{1}$ Technology_Performance $_{i}+\alpha_{2}$ Development_Feasibility $_{i}$ 


$$
+\alpha_{3} \text { Deployment_Feasibility }_{i}+\alpha_{4} \text { Market_Growth }_{i}+\varepsilon_{i}
$$

where $\varepsilon_{i}$ is the error term and $\alpha$ 's are the regression coefficients.

From the extant literature we identified 48 broad terms describing operations design including organization's resources, processes, capabilities, and risk factors. The complete list of terms identified and examined can be found in Table 1. Each broad term represents the synonyms and alternate usage of the term as a verb, adjective, or nouns, which are then listed as keywords, e.g., 'Modular' includes modular, modularity, module(s), component(s). We identified 260 keywords. We then drew upon the technique of content analysis to identify the use of risk mitigation levers by clean technology start-ups. [INSERT TABLE 1 HERE]

Content analysis is a technique for making inferences by objectively and systematically identifying specific characteristics of message [28]. Commonly used in political and socioeconomic research, [18] previously used this technique to assess the market valuation of publicly traded clean technology organizations. Through the information available in the public filing of statements for the ARPA-E funded projects and the project web sites, we examine the specifications for each funded project to identify references to technology performance, development, deployment, and market growth for each technology. Typically such textual information is unstructured, and extracting meaningful information can be time-consuming and difficult. However, a tool called WordStat is specially designed to study textual information, and enables rigorous analysis of vast amounts of textual data.

In the content analysis methodology the frequency of the keyword occurrences reflects the degree of emphasis placed on that concept. We determined the frequency of references to each keyword in the ARPA-E statements, accounting for where the term occurs and examining the 
context for correct use. We went through each project proposal and confirmed the contextual meaning of each term with respect to defining operations design and strategy, product development, technology development and deployment, operational hedging, and environmental technology. We removed all irrelevant uses, duplicates and negative connotations. For example, we sought references to product design choices such as modularity, standards, and customization [6] as exemplified in the following quotes:

“...structural flexibility of the module will render it attractive for deployment in diverse settings such as automotive and data centers with minimal customization."

- University Of Illinois

“...the project will demonstrate a $5 \mathrm{~kW}-10 \mathrm{kWh}$ modular system (scalable to $>10 \mathrm{MW}$ power) and establish a viable manufacturing industry in the US.”

- Eagle Picher Technologies, Inc.

\section{Factor Analysis}

The content analysis identified the frequency of the 48 terms used to describe operations design and hedging for the risk characteristics of highly innovative technologies. However, we wish to understand the underlying structures and relationships existing among these references in order to identify specific determinants of operations design and stretched innovation goals. We employ principal axis factoring with varimax rotation to identify the latent variables. Using these 48 unique variables identified from the content analysis we found that 29 of them loaded onto seven factors--risk mitigation levers--that explained $77.15 \%$ of the inherent variation (eigenvalues greater than one and supported by scree plot). The logical grouping of these characteristics and the similarity to their discussion within the literature also provides face validity for the factor analysis. This grouping presented in Table 2 is as follows: 
PerformanceGoal_Complexity: These institutions target transformational projects with complexity, which pose barriers, challenges and unexpected failures.

PerformanceGoal_Novelty: These institutions target novel projects with disruptive characteristics for customers, but these projects are prone to disastrous risks.

PerformanceGoal_Efficiency: These institutions target projects with critical outcomes, such as low cost, low energy, efficient process and significant greenhouse gas reduction.

Development_Feasibility: These institutions acquire material inputs and offer prototypes to demonstrate development feasibility.

Deployment_Feasibility: These institutions develop production scale and infrastructure for commercialization and sustainability.

MarketGrowth_Potential: These institutions employ rare proof of fit for long-term market growth; in particular, clean technology innovations target reduction in oil use and enhanced national and economic security.

MarketGrowth_Robustness: These institutions demonstrate robust and flexible deployment and delivery for long-term performance.

[INSERT TABLE 2 HERE]

From the content analysis and subsequent factor analysis of 207 highly innovative projects, the factors of PerformanceGoal_Complexity, PerformanceGoal_Novelty, and PerformanceGoal_Efficiency are all indicative of project performance and reflect the traditional concepts of operations strategy and hedging; Development_Feasibility characterize the operations design choices and risks associated with product design and development; Deployment_Feasibility reflect risks and choices for deployment; and MarketGrowth_Potential and MarketGrowth_Robustness align with long term growth strategy of the institution. 


\section{E. Measures}

Dependent Variable. We use the project's funding amount announced publicly by ARPA-E as the measure of project valuation. The project funding amount is exogenously determined by ARPA-E and is independent of our measurement of the explanatory variables.

Explanatory Variables. We have used content analysis and factor analysis to identify seven aggregate variables: PerformanceGoal_Complexity, PerformanceGoal_Novelty, PerformanceGoal_Efficiency, Development_Feasibility, Deployment_Feasibility, MarketGrowth_Potential and MarketGrowth_Robustness. value of each of these variables is calculated by the amount of references an institution makes to the underlying concepts in the ARPA-E project proposals. We use these variables as our measures for risk mitigation levers and as inputs to an econometric model to test their relationship with the value of project funding awarded. The regression analysis method to capture the association with project valuation is described in detail in the following section.

Control. As the risk of the project may increase the further the project proceeds into the future and hence impact the value, we control for the end year of each project with EndYear. In addition, for all models we cluster the standard errors on the seven technology types as defined by ARPA-E to set up a random effect regression analysis. Clustered errors are used based on the assumption is that the observations with a technology type would be correlated. This is similar to using the technology type as a control, but we do not have to reduce the degrees of freedom by the number of technology types.

Table 3 provides the aggregate descriptive statistics for the variables operationalized in the previous section. Table 4 provides additional breakdown of these aggregate statistics by seven technology types. These tables indicate that there is systematic variation between 207 project 
based both on the independent variable and the technology types. We also tested the correlations between the project value and the risk mitigation levers, and did not find collinearity (these tests have been excluded for brevity and are available from the authors).

\section{F. Model Specification}

We present a regression model that incorporates the independent variables determined by factor analysis. By adding control variable EndYear and $\varepsilon_{i}$ as the error term for project $i$, we define the risk mitigation levers-valuation model as:

Ln FundingValue $_{i}=\beta_{0}+\beta_{1}$ PerformanceGoal_Complexity $_{i}+\beta_{2}$ PerformanceGoal_Novelty $_{i}$

$$
\begin{aligned}
& +\beta_{3} \text { PerformanceGoal_Efficiency }_{i}+\beta_{4} \text { Development_Feasibility }_{i} \\
& +\beta_{5} \text { Deployment_Feasibility }_{i}+\beta_{6} \text { MarketGrowth_Potential }_{i} \\
& +\beta_{7} \text { MarketGrowth_Robustness }_{i}+\beta_{8} \text { EndYear }_{i}+\varepsilon_{i}
\end{aligned}
$$

The $\beta$ s refer to the potential size of the effect of risk mitigation levers on project valuation, the managerial implication being that the significance or not of these factors will increase the understanding of the types of operation design and hedging activities that impact project valuation. We use a random effects regression with the value of funding awarded to the project as the dependent variable (see Table 5) and cluster on the technology type to correct for potential correlations among different institutions developing the same technology [25]. We use White standard errors which are robust to heteroskedasticity [56]. To allow for the possibility that the institution type accounts for differences in project valuation, we tested the specified regression model for the four institution types: mature firms, start-ups, universities and non-profits, and research institutes.In doing so, we built five models for a comparative study. We tested each 
model for any potential collinearity, the VIF scores subsequent to the regression analysis indicated that collinearity was not an issue.

Model 1 tests the relationship between project risk mitigation levers and project value for all institutions in our dataset (pooled sample). In model 2 we only include mature firms as classified by ARPA-E of firms of middle size and with larger than 500 employees. In model 3 we followed institutions classified as commercial start-up by ARPA-E. We further consulted the definition by US Small Business Administration and looked up each institution on business datasets (Company Dossier, Hoovers, Capital IQ) for the average number of employees for the preceding twelve months or on sales volume averaged over a three-year period. Similarly, we used ARPAE classifications for model 4 on universities and non-profits and model 5 on research institutions. [INSERT TABLE 5 HERE]

\section{IV.RESULTS}

\section{A. Analysis of Project Valuation}

In the first model we pool data from all institution types to test the association between project risk mitigation levers (performance goals, development and deployment feasibility, and market growth) and project valuation. $\mathrm{H} 1$ predicts a relation between the nature of performance goal and project valuation. We examine the regression coefficients in Table 5 to determine which performance goals are significantly related to project valuation. The coefficient for performance goal for efficiency in model 1 is negative (-36.79) and significant $(\mathrm{p}<0.1)$, indicating that $\mathrm{H} 1$ is negatively and partially supported. $\mathrm{H} 2$ predicts a positive relation between feasible technology development and project valuation. The coefficient is $-428.78(\mathrm{p}<0.05)$ in model 1 . Hence, H2 is inversely supported, which shows a negative association that feasible development determined by operations design and hedging may reduce project valuation. 
$\mathrm{H} 3$ is a test of the positive relation between feasible technology deployment and project valuation. We find support for this relation $(\mathrm{p}<0.1)$ in model 1 , which predicts that feasible deployment determined by operations design and hedging improves project valuation (coefficient: 393.95). H4 predicts a relation between market growth-oriented project proposal and project valuation. We find a negative relation with coefficient $-77.29(\mathrm{p}<0.05)$ for risk mitigation lever defining the project's potential for growth, but no relation for its robustness. Thus, H4 is negatively and partially supported in this aggregate analysis.

$\mathrm{H} 5$ tests the impact of institution type on the association between project risk mitigation levers and project valuation by examining models for relevant subsamples. In model 2 we run the regression model for mature firms, in model 3 for start-ups, in model 4 for universities and nonprofits, and in model 5 for research centers. Table 5 presents these models. First, the regression coefficients for performance goal of novelty and efficiency are, respectively, $-304.777(\mathrm{p}<0.05)$ and $86.375(\mathrm{p}<0.1)$ for the mature firms; the other levers are not found to be significant. Performance goal of complexity $(-200.191 ; \mathrm{p}<0.01)$ and efficiency $-91.283 ; \mathrm{p}<0.01)$ for the start-ups and performance goal of complexity $(79.430 ; p<0.05)$ for the research centers show relationship with project valuation. Thus, H5a.i), ii) and $i v$ ) are partially supported in the subsamples except for universities and non-profits, indicating that our finding in $\mathrm{H} 1$ is moderated with institution type.

Second, examining regression coefficients, development feasibility has the largest negative relationship with project valuation for start-ups $(-630,804 ; \mathrm{p}<0.1)$ followed by research centers $(-580,409 ; \mathrm{p}<0.05)$. The largest positive relationship for deployment feasibility is obtained for research centers $(1,807,000 ; \mathrm{p}<0.01)$ followed by start-ups $(485,950 ; \mathrm{p}<0.05)$. These results partially support H5b.ii) and iv), and H5c.ii) and $i v$ ), which hypothesized that the development 
and deployment feasibilities would be moderated by each institution type. Finally, only market growth for robustness is found to be significant for the universities and non-profits, and research centers (the coefficients are $-115,586$ and 380,285, respectively, both significant at 0.01 or better), so H5d.iii) and iv) are partially supported.

\section{B. Further Analysis of Institution and Technology Types}

Our analysis found partial support (for H5) in models 2-5 based on the sub-sample data by institution type, and also found partial support for $\mathrm{H} 1-\mathrm{H} 4$ in when these data were pooled into a portfolio of investments. To assess the portfolio data in terms of risk distribution by institution type, we presented in Table 6 the coefficient of variation (COV) of independent variables in the entire portfolio (a.k.a. pool sample) by the four institution types (a.k.a. sub-samples): mature firms, start-ups, universities and non-profits, and research centers. For ease of comparison the sub-sample COV breakdown is normalized within each row and the results are sorted in the descending order for the pooled sample. Further, Table 7 lists the COV in control variables (i.e., by technology type) in the descending order, and their normalized breakdown by row.

$\mathrm{COV}$ is a measure of the variability, i.e., a proxy for risk, within the portfolio or its subsample. This measure of risk assessment is consistent with that used in prior studies [37]. In our analysis a higher value of COV indicates higher degree of risk. Using these findings, we developed a more nuanced assessment of the portfolio data in terms of the distribution of risk by the institution and technology types. Such a measure not only allows us to assess the extent to which each risk mitigation lever was associated with a specific type of institution, but also captures the variation in the risk with respect to technology type, i.e., the extent to which an institution finds innovation management on that particular clean technology risky. Specifically, in Table 6 the COV values for development and deployment feasibility are the highest (3.46 and 
2.61, respectively), indicating the highest risk mitigation lever. In Table 7 the highest COV value is at 0.61 for energy storage development projects, indicating the highest level of risk, and the lowest COV value is at 0.49 for the rare earth alternatives in technology projects, indicating the lowest level of risk.

[INSERT TABLE 6 HERE]

[INSERT TABLE 7 HERE]

\section{DISCUSSION}

Our main contribution in this study is to develop the understanding of operations design characteristics, which determine risk mitigation levers that in turn influence the valuation of highly innovative projects for different institutions. Recent interest in clean technology and limited financing of high risk clean technology and energy ventures have underlined the need for considering non-financial risk mitigation tools as one strategy to achieve success. In spite of this, there have been relatively few empirical studies that specifically examined operations design and hedging as determinants of valuation for highly innovative projects [2]. Also, to the best of our knowledge, extant research has not examined operations design for managing the risk of highly innovative technologies. Next we discuss key finding and their managerial, policy and theory implications.

\section{A. The Influence of Design Characteristics on Project Valuation}

In particular, we find that deployment feasibility is significantly and positively associated with project valuation (consistent with $\mathrm{H} 3$ ), suggesting that improved deployment feasibility raises valuation. We find this rise in valuation significant for the overall sample and the subsamples with only start-ups and only research centers. We find negative association for three risk mitigation levers (performance goals of efficiency, development feasibility, and potential market 
growth), indicating that operations design decisions for these would lead to reduced project valuation. However, this does not necessarily mean that these risk mitigation levers are less important in financing. This suggests that when different institutions are competing for the same funds, feasible deployment is a significant differentiator for project valuation.

When the sample is disaggregated by institution type, we find substantial differences in value enhancing risk mitigation levers. This supports the viewpoint that different institutions operate with different risk exposure, sources and incentive structures [3]. With the sub-sample of mature firms we find partial support for H5a.i) (technology performance goals of novelty and efficiency), but no support for other risk mitigation levers. In fact, unlike the case for the pooled sample we find positive support for performance plans for efficiency, but no support for deployment feasibility. Thus, the role of technology performance is critical for the project valuation in an industry with mature firms. This supports the product development research on performance examined mainly for large and mature organizations [31], [48], [55]. Our findings suggest that in an industry dominated by mature firms managers target efficient performance, rather than demonstrate novelty in technology performance.

When the sub-sample consisted only of either start-ups or research centers, we find partial support for H5a (i.e., technology performance is moderated) and full support for H5b and H5c (i.e., development and deployment feasibility are moderated). Similar to pooled sample, deployment feasibility generates the largest valuation upon design for industries of start-ups or research centers. In addition, research centers also gain project value by targeting complicated technologies as well as robust market growth (H5d.iv). This supports the economic viewpoint that scientists in research centers are rewarded for the production of economic knowledge rather than scientific knowledge while researchers at universities and non-profits are encouraged to 
share their work [3]. Therefore, market growth plans may hurt their project valuation in financing. In our analysis we obtain partial support for H5d.iii) in the setting with universities and non-profits.

\section{B. Role of Portfolio Risk}

Though we find support for hypotheses of pooled sample and individual institution types, the significant negative effects for $\mathrm{H} 1, \mathrm{H} 2$ and $\mathrm{H} 4$ were not expected. Observed risk level, by institution and technology type, using COV measures from our descriptive analysis provide additional details that are pertinent. First, our results show that the feasibility construct for development is associated with the highest pooled risk, and the goal to improve technology and energy efficiency is associated with the lowest risk. This finding is consistent with negative support for $\mathrm{H} 2$ in regression analysis. Second, there is variation in the normalized contribution to risk by institution type. For instance, the projects at research centers are the least risky in terms of development feasibility, whereas the projects at mature firms are the least risky in terms of deployment feasibility. Finally, in addition to institution types, we examine the technology types individually for variation in the risk in terms of technologies. We find that energy storage development projects are deemed to be the most risky (i.e., they have the highest COV) and the rare earth alternatives in technology projects are the least risky. Here again, there is variation in the normalized contribution to risk by institution type. For instance, the portfolio of projects at mature firms is the least risky for energy storage. Consistent with conventional wisdom, projects at start-ups are not the lowest risk options.

\section{Managerial Implications}

From a managerial perspective, our work suggests that managers seeking financing consider the pool of applicants and technology type in their applications and insure that their projects are 
designed in favor of reducing operational risk to enhance project value. In an industry with different types of institutions, we found evidence that the financiers might be seeking results past testing stage to finance critically uncertain projects; particularly, technology deployment for the consumer market increases project value. Rather than a long-term market growth plan, we suggest that the firm have a technology adoption plan at the funding stage. These results seem to support the practical view that highly innovative technologies require infrastructure to win headon-competition with the current infrastructure [16]. For example, electric vehicles need significant investments in the buildup of charging stations as well as winning consumers over the existing convenience of infrastructure for gasoline powered vehicles. It would also be interesting to replicate this research with different combinations of institution types, which is a potential direction for future research.

We explain these implications through post-hoc examination of FastCAP Systems, one of the start-ups within our dataset. FastCAP invented an improvement of an energy-storage device called the ultracapacitor [44]. Ultracapacitors have the potential to store energy, which is much larger than standard capacitors, because they are made using activated carbon nano-technology coating. While applying for ARPA-E funding, FastCAP had explained product architecture and application design, and patented its core technology [45]. Further, the company also listed the best suited applications for its technology from early on. With money available for the next 2 years, CEO Signorelli's goal was to achieve the technology's practical and commercial promise [44]. Company website reported on a potential set of target markets, ranging from automotive, to tidal energy, to geothermal solutions (www.fastcapsystems.com). Given the commercial potential for the underlying technology, our post-hoc work indicates that the ability to adapt a market is deemed feasible. Our regression analysis shows that the funding process values a 
feasible deployment strategy into a specific target market. Our COV analysis shows that demonstrating proof for development and deployment feasibility reduces the risk exposure of FastCAP, making it a viable candidate for financing.

\section{Public Policy Implications}

From a public policy perspective, there has been a growing literature that calls for specifying and monitoring the desired performance goal, and risks, at the disaggregate levels of decision making [12], [57]. The variations observed in our descriptive data, and our regression findings support the case for disaggregated policy implementation. From a theory perspective, one would expect that a sub-sample with higher mean, and lower COV, would be rewarded with higher valuation along each relevant dimension of performance. However, there is no discernible pattern in the normalized mean (i.e., reward) and COV (i.e., risk) measures and the significant associations established in the regressions. This suggests that there may be opportunity for ARPA-E to look into its valuation and portfolio management policies and construct portfolios that provide a balance between the reward and risk for each type of institution that they are funding. It is also possible to conduct an optimization analysis of the portfolio assignment - we leave that as an exercise for future work.

\section{E. Theory Implications}

This research contributes to studies on dynamic RBV, operations management and entrepreneurship by showing how the valuation of highly innovative projects depends on the alignment of organization's resources and processes with risks (that determines risk mitigation levers). This is notable since the use of operations design to mitigate value degradation due to uncertainty for highly innovative technologies, like clean technology, has been scantly addressed in the operations management and entrepreneurship literature. Operational hedging studies have 
primarily focused on the context of rather mature firms, and have mostly been studied with organizations that are not necessarily encumbered by pressing financial constraints [29], [54]. Thus, our study makes a contribution to the literature on operations management and entrepreneurship with an empirical examination of actual project valuation and risk mitigation levers is for highly innovative institutions of different types.

With respect to theory development, our study also contributes by extending research in the area of dynamic RBV in which previous work has focused primarily on the organizational capabilities and cognitive factors for human capital to create strategic value [4]. Our study introduces another perspective that project valuation may be obtained from mitigating resource related risks through operations design. We also address the dynamic RBV by proposing a lifecycle perspective that is required to frame the choices of operations design, specifically when considering the risks involved in getting the product from design to market commercialization. Our results point out that through operations design, institutions may manage risk exposure with a dynamic portfolio of activities. Hence, our use of operations design, hedging and RBV of the firm provide a direction to advancing more dynamic variants of the RBV.

\section{CONCLUSION}

Our study introduced a risk mitigation perspective using operations design to provide insights into the relationship between risk mitigation levers and project valuation. Insights from our analysis go beyond simply looking for financing from traditional sources like banks and VCs and encourage developers, researchers and entrepreneurs to design their projects characterized by hedging tools that could be readily available and lead to enhanced project valuation. Our results are revealing in terms of factors that drive valuation, while ARPA-E is steering important 
technologies from basic science to commercialization. It is clear that operations design issues (such as focus on the infrastructure) are valued because they mitigate strategic risks.

However, these findings come from an exploratory study that comes with a number of limitations, both on the operationalization and on the theory fronts. We have not accounted for fixed effect (in terms of lack of variation within sub-sectors) as well as selection bias issues. It would be ideal for future work to examine both the projects that were funded as well as projected that were denied funding. It would also be illustrative to examine how these funded institutions adapt to market realities while their technologies evolve, and when allied public policy (such as, introduction of carbon tax) is finalized. On the theory side, it would be illuminating to further consider how the resource bundles associated with basic science, applied science and technology commercialization stages evolve. We identify these as assessments that ought to provide important findings for the field of technology management, entrepreneurship and public policy, especially in the energy domain.

\section{REFERENCES}

[1] S. Ahmad, D. N. Mallick and R. G. Schroeder, "New product development: Impact of project characteristics and development practices on performance", J. of Product Innovation Management, vol. 30, pp. 331-348, 2013.

[2] G. Allayannis, J. Ihrig and J. P. Weston, "Exchange rate hedging: Financial vs. operational strategies," American Economic Rev., vol. 91, no. 2, pp. 391-395, 2001

[3] D. B. Audretsch and P. E. Stephan, "Knowledge spillovers in biotechnology: sources and incentives," J. Evol. Econ., vol. 9, pp. 97-107, 1999.

[4] ARPA-E, "Energy Transformation Acceleration Fund Advanced Research Projects Agency Energy," FY 2011 Congressional Fund, 12, 2011.

[5] A. Bajaj, S. Kekre and K. Srinivasan, "Managing NPD: Cost and schedule performance in design and manufacturing," Management Science, vol. 50, no. 4, pp.527-536, 2004.

[6] C. Y. Baldwin and K. B. Clark, Design Rules: The Power of Modularity, MIT Press: Cambridge, MA, 1999.

[7] J. Barney, "Firm Resources and Sustained Competitive Advantage," J. Mgt., vol. 17, no. 1, pp. 99-112, 1991. 
[8] J. Barney, M. Wright, and D. J. Ketchen, "The resource-based view of the firm: Ten years after 1991,” J. Mgt., vol. 27, pp. 625-641, 2001.

[9] A. Berger and G. Udell, "Small business and debt finance," Handbook of entrepreneurship research, pp. 299-328, 2005.

[10] A. Bhide, The origin and evolution of new businesses, Oxford University Press, 2000.

[11] T. R. Browning and S. D. Eppinger, "Modeling impacts of process architecture on cost and schedule risk in product development," IEEE Trans. Eng. Mgt., vol. 49, no. 4, pp. 428-442, 2002.

[12] A. K. Carrie, A. Gupta, G.Shrimali, and A. Albert, "Is disaggregation the holy grail of energy efficiency? The case of electricity," Energy Policy, vol. 52, pp. 213-234, 2013.

[13] G. Cassar, "The financing of business start-ups," J. Business Venturing, vol. 19, no. 2, pp. 261-283, 2004.

[14] T. Casciaro and M. J. Piskorski, "Power imbalance, mutual dependence, and constraint absorption: A closer look at resource dependence theory," Adm. Sci. Quarterly, vol. 50, no. 2, pp. 167-199, 2005.

[15] K. Cheung, "Financing Clean Energy Projects in Troubled Times. Asia Clean Energy Forum, Manila," Accessed March, 2012 at http: Ilwww.adb.org, 2009.

[16] C. M. Christensen, S. Talukdar, R. Alton and M. B. Horn, "Picking Green Tech's Winners and Losers," Stanford Social Innovation Rev., pp. 30-35, 2011.

[17] R. G. Cooper and E. J. Kleinschmidt, Success Factors for New-Product Development: Wiley International Encyclopedia of Marketing, 2010.

[18] J. Davies and N. Joglekar, "The market value of modularity and supply chain integration: Theory and evidence from the solar photovoltaic industry," Working paper, 2010.

[19] D. J. Denis, "Entrepreneurial finance: an overview of the issues and evidence," J. Corporate Finance, vol. 10, no. 2, pp. 301-326, 2004.

[20] A.K. Dixit and R.S. Pindyck, Investment under uncertainty, Princeton University Press: New Jersey, 1994.

[21] J. T. Eckhardt, S. Shane and F. Delmar, "Multistage selection and the financing of new ventures," Mgt. Sci., vol. 52, no. 2, pp. 220-232, 2006.

[22] S. S. Erzurumlu, F. Tanrisever, and N. Joglekar, "Operational Hedging Strategies to Overcome Financial Constraints during Clean Technology Start-up and Growth," in Advanced Analytics for Green and Sustainable Economic Development: Supply Chain Models and Financial Technologies, Z. Luo, Ed. Hershey: IGI Publishing, pp. 112-131, 2011.

[23] W. Guay and S. P. Kothari, "How much do firms hedge with derivatives?" J. Financial Economics, vol. 70, no. 3, pp. 423-461, 2003.

[24] R. H. Hayes and S. C. Wheelwright, Restoring our competitive edge: Competing through manufacturing, Wiley: New York, 1984.

[25] D. Hedeker and R. D. Gibbons, "A random-effects ordinal regression model for multilevel analysis," Biometrics, pp. 933-944, 1994. 
[26] C. E. Helfat and M. A. Peteraf, "The dynamic resource-based view: capability lifecycles," Strategic Mgt. J., vol. 24, no. 10, pp. 997-1010, 2003.

[27] R. M. Henderson and R. G. Newell. Accelerating Energy Innovation: Insights from Multiple Sectors, University of Chicago Press, 2011.

[28] O. R. Holsti, Content analysis for the social sciences and humanities, Addison-Wesley Publishing: Reading, MA, 1969.

[29] A. Huchzermeier and M. A. Cohen, "Valuing operational flexibility under exchange rate risk," Ops. Research, vol. 44, no. 1, pp. 100-113, 1996.

[30] A. B. Jaffe, R. G. Newell, and R. N. Stavins, "Technology policy for energy and the environment, Innovation Policy and the Economy, vol. 4, pp. 35-68, 2004.

[31] V. Krishnan and K. T. Ulrich, "Product development decisions: A review of the literature," Mgt. Sci., vol. 47, no. 1, pp. 1-21, 2001.

[32] M. LaMonica, "Clean-tech bubble talk is a red herring," Retrieved March 10, 2010, from http://news.cnet.com/8301-11128_3-10051792-54.html, Sept. 2008.

[33] J. Lerner, "The government as venture capitalist: The long-run impact of the SBIR program," J. Business, vol. 72, no. 3, pp. 285-318, 1999.

[34] J. Lerner, "When bureaucrats meet entrepreneurs: The design of effective 'public venture capital' programmes," The Economic Journal, vol. 112, no. 477, pp. F73-F84, 2002.

[35] D. N. Mallick and R. G. Schroeder, "An integrated framework for measuring product development performance in high technology industries", Prod. and Ops. Mgt., vol. 14, pp. 142-158, 2005.

[36] M. H. Meyer and J. M. Utterback, "Product development cycle time and commercial success," IEEE Trans. Eng. Mgt., vol. 42, no. 4, pp. 297-304, 1995.

[37] N. A. Morgan, L. L. Rego, "Brand portfolio strategy and firm performance," J. of Marketing, vol. 73, pp. 59-74, 2009.

[38] NYTimes, "Solar industry learns lessons in Spanish sun,” Jul. 2010.

[39] NYTimes, "No home run yet' for ARPA-E, but chief says 'motivated' team's on track," Aug. 2011.

[40] R. Pernick, C. Wilder and I. Wormick, Clean Energy Trends 2012, Clean Edge, Incorporated, 2012.

[41] PricewaterhouseCoopers. "Pharma 2020: Virtual R\&D - Which path will you take?” 2007.

[42] R. Sanchez and J. T. Mahoney, "Modularity, flexibility, and knowledge management in product and organization design," Strategic Mgt. J., vol. 17, pp. 63-76, 1996.

[43] R. G. Schroeder, K. A. Bates and M. A. Junttila, "A resource-based view of manufacturing strategy and the relationship to manufacturing performance," Strategic Mgt. J., vol. 23, no. 2, pp. 105-117, 2002.

[44] Science, "Taken for granted: A shot at transforming America's energy future," 2010.

[45] J. Schindall, J. Kassakian and R. Signorelli, "Engineered structure for charge storage and method of making," U.S. Patent \# US 2007/0258192.

[46] W. Skinner, Manufacturing-missing link in corporate strategy: Harvard Business Review, 1969. 
[47] F. Tanrisever, S. S. Erzurumlu and N. Joglekar, "Production, process investment and the survival of debt-financed start-ups," Prod. and Ops. Mgt., vol. 21, no. 4, pp. 637-652, 2012.

[48] M.V. Tatikonda and S. R. Rosenthal, "Technology novelty, project complexity, and product development project execution success: a deeper look at task uncertainty in product innovation", IEEE Transactions on Engineering Management, vol. 47, no. 1, pp. 74-87, 2000.

[49] S. Toor and S. O. Ogunlana, "Beyond the 'iron triangle': Stakeholder perception of key performance indicators (KPIs) for large-scale public sector development projects," International J. of Project Management, vol. 28, no. 3, pp. 228-236, 2010.

[50] A. J. Triantis, "Real options and corporate risk management," J. of Applied Corporate Finance, vol. 13, no. 2, pp. 64-73, 2000.

[51] P. Tufano, "Who manages risk? An empirical examination of risk-management practices in the gold mining industry," J. Finance, vol. 51, no. 4, pp. 1097-1137, 1996.

[52] K. T. Ulrich, "The role of product architecture in the manufacturing firm," Res. Policy, vol. 24, pp. 419-440, 1995.

[53] K. T. Ulrich and S. Pearson, "Assessing the importance of design through product archaeology,” Mngment. Sci., vol. 44, no. 3, pp. 352-369, 1998.

[54] J. A. van Mieghem, "Capacity management, investment, and hedging: Review and recent developments," Manufacturing and Service Ops. Mgt., vol. 5, no. 4, pp. 269-302, 2003.

[55] J. A. van Mieghem, Operations strategy: Principles and practice, Dynamic Ideas: Belmont, MA, 2008.

[56] H. White, "A heteroskedasticity-consistent covariance matrix estimator and a direct test for heteroskedasticity,”. Econometrica, vol. 48, no. 4, pp. 817-838, 1984.

[57] J. Yuan, J. Kang, S. Zhao and Z. Hu, "Energy consumption and economic growth: Evidence from China at both aggregated and disaggregated levels", Energy Econ., vol. 30, no. 6, pp. 3077-3094, 2008. 
Figure 1. Research Framework

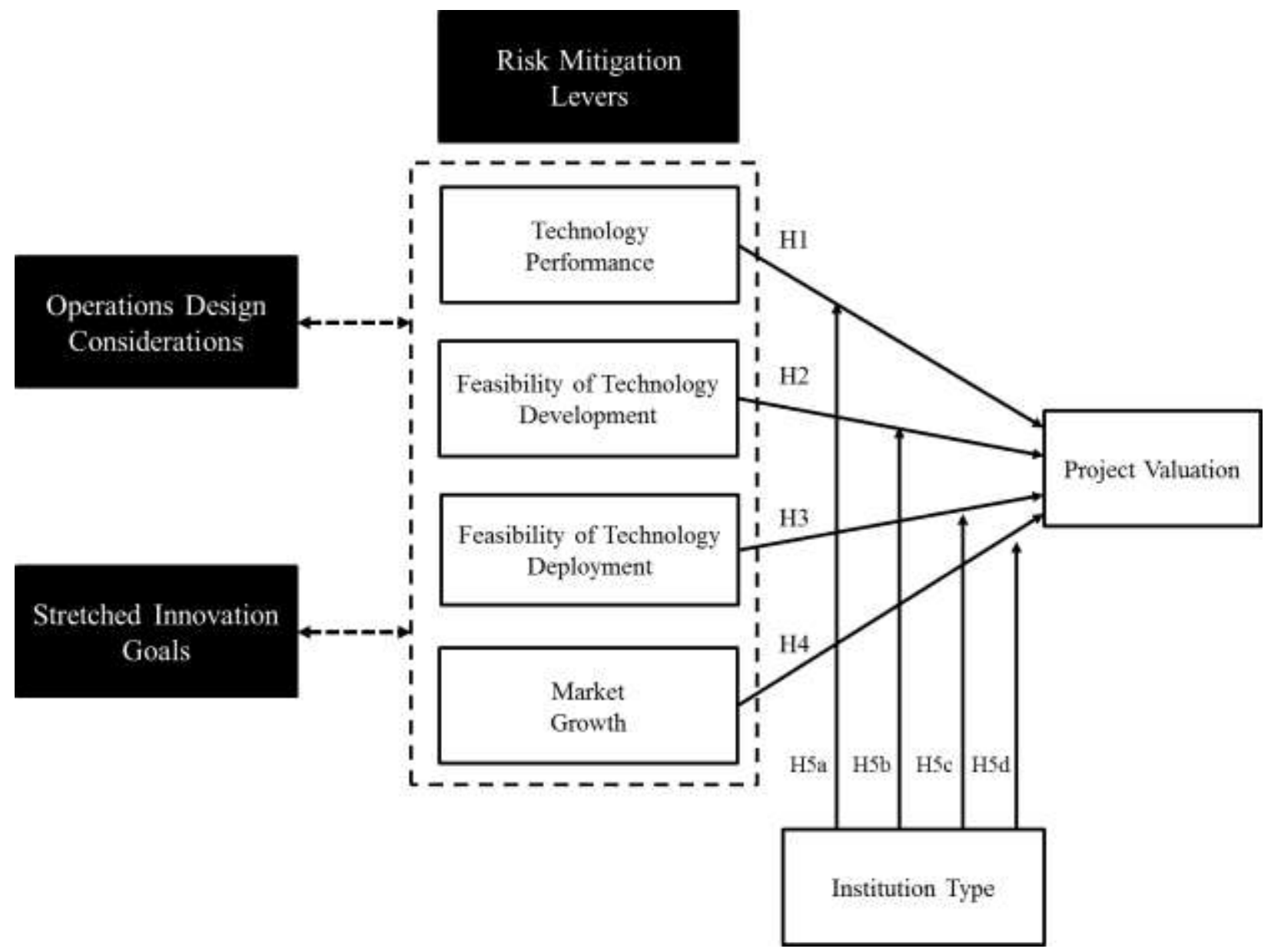

Table 1. Search keywords for operations design considerations and stretched innovation goals

\begin{tabular}{|c|c|}
\hline Search Terms & Source \\
\hline $\begin{array}{l}\text { Innovation, Transform, Barrier, Critical, Fail, Customer, User, } \\
\text { Rare, Disrupt }\end{array}$ & $\begin{array}{l}\text { Classification of competitive } \\
\text { strategies [7], [55] }\end{array}$ \\
\hline $\begin{array}{l}\text { Performance, Complex, Flexible, Robust, Expertise, Capacity, } \\
\text { Integration, Market growth }\end{array}$ & Operations design and strategy [55] \\
\hline $\begin{array}{l}\text { Design, Technology Efficiency, Speed, Safety, Quality, } \\
\text { Modular, Prototype, Early stage, Demonstrate feasibility }\end{array}$ & $\begin{array}{l}\text { Product design and development } \\
\text { [4], [31] }\end{array}$ \\
\hline $\begin{array}{l}\text { Manufacturing capability, Process Efficiency, Low cost, Low } \\
\text { cost production, Material inputs, Yield increase }\end{array}$ & Manufacturing [25], [46] \\
\hline $\begin{array}{l}\text { Test scale, Infrastructure, Intellectual property, Mature, } \\
\text { Production scale, Commercialize, Deployment and Delivery }\end{array}$ & $\begin{array}{l}\text { Technology financing and } \\
\text { commercialization [22] }\end{array}$ \\
\hline Hedge, Risk, Challenge, Unexpected, Disaster & $\begin{array}{l}\text { Operational hedging and risk } \\
\text { management [54] }\end{array}$ \\
\hline $\begin{array}{l}\text { Sustainability, Greenhouse gas reduction, Oil reduction and } \\
\text { security, Energy security, Low energy }\end{array}$ & $\begin{array}{l}\text { Determinants for environmental } \\
\text { technology [22], [30] }\end{array}$ \\
\hline
\end{tabular}


Table 2. Identified Factors for Risk Mitigation Levers

\begin{tabular}{|c|c|c|c|c|c|c|c|}
\hline Variable & $\begin{array}{c}\text { Factor1 } \\
\text { PerformanceGoal } \\
\text { _Complexity }\end{array}$ & $\begin{array}{c}\text { Factor2 } \\
\text { PerformanceGoal } \\
\quad \text { Novelty } \\
\end{array}$ & $\begin{array}{c}\text { Factor3 } \\
\text { PerformanceGoal } \\
\text { _Efficiency } \\
\end{array}$ & $\begin{array}{c}\text { Factor4 } \\
\text { Development } \\
\text { _Feasibility } \\
\end{array}$ & $\begin{array}{c}\text { Factor5 } \\
\text { Deployment } \\
\text { _Feasibility } \\
\end{array}$ & $\begin{array}{c}\text { Factor6 } \\
\text { MarketGrowth } \\
\text { _Potential }\end{array}$ & $\begin{array}{c}\text { Factor7 } \\
\text { MarketGrowth } \\
\text { _Robust }\end{array}$ \\
\hline Unexpected & 0.888 & & & & & & \\
\hline Failure & 0.842 & & & & & & \\
\hline Complexity & 0.827 & & & & & & \\
\hline Safety & 0.825 & & & & & & \\
\hline Transform & 0.756 & & & & & & \\
\hline Barrier & 0.679 & & & & & & \\
\hline Challenge & 0.436 & & & & & & \\
\hline Disaster & & 0.856 & & & & & \\
\hline Disruption & & 0.784 & & & & & \\
\hline Customer & & 0.537 & & & & & \\
\hline Low Energy & & & 0.705 & & & & \\
\hline Process Efficiency & & & 0.679 & & & & \\
\hline Critical & & & 0.427 & & & & \\
\hline Greenhouse Gas Reduction & & & 0.493 & & & & \\
\hline Low Cost & & & 0.517 & & & & \\
\hline Demonstrate Feasibility & & & & 0.368 & & & \\
\hline Material Inputs & & & & 0.339 & & & \\
\hline Prototype & & & & 0.333 & & & \\
\hline Commercialization & & & & & 0.595 & & \\
\hline Sustainability & & & & & 0.547 & & \\
\hline Infrastructure & & & & & 0.467 & & \\
\hline Production Scale & & & & & 0.400 & & \\
\hline Rare & & & & & & 0.761 & \\
\hline Market Growth & & & & & & 0.550 & \\
\hline Oil Reduction \& Security & & & & & & 0.484 & \\
\hline Robust & & & & & & & 0.691 \\
\hline Deployment \& Delivery & & & & & & & 0.567 \\
\hline Flexible & & & & & & & 0.404 \\
\hline Performance & & & & & & & 0.364 \\
\hline
\end{tabular}

Method: Principal axis factoring with varimax rotation.

Table 3. Descriptive Statistics for All Institution Types (Pooled)

\begin{tabular}{llllll}
\hline Variable & Obs. & Mean & Std. Dev. & Min & Max \\
\hline Funding Value & 207 & $2,852,014$ & $1,722,041$ & 250,000 & $9,003,198$ \\
PerformanceGoal_Complex & 207 & 1.343 & 2.798 & 0 & 14 \\
PerformanceGoal_Novelty & 207 & 0.860 & 1.256 & 0 & 7 \\
PerformanceGoal_Efficiency & 207 & 12.643 & 6.185 & 1 & 32 \\
Development_Feasibility & 207 & 0.116 & 0.402 & 0 & 2 \\
Deployment_Feasibility & 207 & 0.300 & 0.780 & 0 & 8 \\
MarketGrowth_Potential & 207 & 2.391 & 2.960 & 0 & 14 \\
MarketGrowth_Robustness & 207 & 2.763 & 3.245 & 0 & 15 \\
\hline
\end{tabular}


Table 4. Descriptive Statistics for all technology types (Pooled)

\begin{tabular}{lccccc}
\hline Grant Value \$ by Technology Type & $\begin{array}{c}\text { Pooled } \\
\text { Observations }\end{array}$ & Mean & $\begin{array}{c}\text { Standard } \\
\text { Deviation }\end{array}$ & Minimum & Maximum \\
\hline Delivery of electrical power technology & 27 & $2,915,198$ & $1,692,580$ & 998,619 & $8,325,400$ \\
Energy storage & 67 & $2,799,050$ & $1,700,693$ & 556,732 & $7,200,000$ \\
Thermo devices & 16 & $2,423,967$ & $1,452,979$ & 400,000 & $5,991,065$ \\
Electricity network & 17 & $2,660,348$ & $1,402,230$ & 821,880 & $5,006,011$ \\
Carbon capture & 18 & $2,535,629$ & $1,491,297$ & 560,809 & $5,297,254$ \\
Biofuels & 45 & $3,490,023$ & $2,102,529$ & 250,000 & $9,003,198$ \\
Rare earth alternatives in technologies & 17 & $2,201,079$ & $1,086,283$ & 397,433 & $4,475,417$ \\
\hline
\end{tabular}

Table 6. COV Values for the Pool Sampled and Normalized COVs for its Sub-Samples

\begin{tabular}{lccccc}
\hline & Pooled & $\begin{array}{c}\text { Mature } \\
\text { Firms }\end{array}$ & Start-ups & $\begin{array}{c}\text { Universities } \\
\text { \& Non } \\
\text { Profits }\end{array}$ & $\begin{array}{c}\text { Research } \\
\text { Institutes }\end{array}$ \\
\cline { 2 - 6 } Independent Variables & COV & \multicolumn{4}{c}{ Normalized COV } \\
\hline Development_Feasibility & 3.46 & $196 \%$ & $95 \%$ & $106 \%$ & $50 \%$ \\
Deployment_Feasibility & 2.61 & $91 \%$ & $98 \%$ & $86 \%$ & $108 \%$ \\
PerformanceGoal_Complexity & 2.08 & $90 \%$ & $93 \%$ & $110 \%$ & $93 \%$ \\
PerformanceGoal_Novelty & 1.46 & $91 \%$ & $83 \%$ & $115 \%$ & $91 \%$ \\
MarketGrowth_Potential & 1.24 & $89 \%$ & $93 \%$ & $105 \%$ & $82 \%$ \\
MarketGrowth_Robustness & 1.17 & $83 \%$ & $96 \%$ & $115 \%$ & $93 \%$ \\
PerformanceGoal_Efficiency & 0.49 & $104 \%$ & $110 \%$ & $91 \%$ & $104 \%$ \\
\hline
\end{tabular}

Table 7. COV by Technology Type for the Pool Sample and Normalized COVs for its SubSamples

\begin{tabular}{|c|c|c|c|c|c|c|}
\hline & \multirow{2}{*}{$\begin{array}{c}\text { Coefficient of Variation } \\
\text { by Technology Type }\end{array}$} & \multirow{2}{*}{$\begin{array}{c}\text { Pooled } \\
\text { COV }\end{array}$} & $\begin{array}{c}\text { Mature } \\
\text { Firms }\end{array}$ & Start-ups & $\begin{array}{l}\text { niversiti } \\
\text { \& Non } \\
\text { Profits }\end{array}$ & $\begin{array}{c}\text { Research } \\
\text { Centers }\end{array}$ \\
\hline & & & \multicolumn{4}{|c|}{ Normalized COV } \\
\hline 1 & Energy storage & 0.61 & $83 \%$ & $85 \%$ & $109 \%$ & $82 \%$ \\
\hline 2 & Biofuels & 0.60 & $128 \%$ & $97 \%$ & $94 \%$ & $40 \%$ \\
\hline 3 & Thermo devices & 0.60 & $67 \%$ & $148 \%$ & $92 \%$ & N/A \\
\hline 4 & Carbon capture & 0.59 & $45 \%$ & $103 \%$ & $103 \%$ & $101 \%$ \\
\hline 5 & Delivery of elec. power technology & 0.58 & $84 \%$ & $89 \%$ & $104 \%$ & N/A \\
\hline 6 & Electricity network & 0.53 & $123 \%$ & $79 \%$ & $120 \%$ & $54 \%$ \\
\hline 7 & Rare earth alternatives in technologies & 0.49 & $43 \%$ & N/A & $120 \%$ & $10 \%$ \\
\hline
\end{tabular}


Table 5. Regression Results. Dependent variable: Funding Value

\begin{tabular}{|c|c|c|c|c|c|c|c|c|}
\hline \multirow{3}{*}{$\begin{array}{l}\text { Independent Variables } \\
\text { PerformanceGoal_Complexity }\end{array}$} & \multicolumn{2}{|l|}{$\begin{array}{l}\text { Model } 1 \\
\text { Pooled }\end{array}$} & $\begin{array}{c}\text { Model } 2 \\
\text { Mature Firms }\end{array}$ & \multicolumn{2}{|l|}{$\begin{array}{l}\text { Model } 3 \\
\text { Start-ups }\end{array}$} & $\begin{array}{c}\text { Model } 4 \\
\text { Universities \& } \\
\text { Non-Profits }\end{array}$ & \multicolumn{2}{|c|}{$\begin{array}{c}\text { Model } 5 \\
\text { Research Centers }\end{array}$} \\
\hline & $-57,709$ & & $-37,131$ & $-200,191$ & $* * *$ & $-48,620$ & 79,430 & $* *$ \\
\hline & $(36,428)$ & & $(69,526)$ & $(59,087)$ & & $(57,761)$ & $(32,274)$ & \\
\hline \multirow[t]{2}{*}{ PerformanceGoal_Novelty } & $-128,973$ & & $-304,777 * * *$ & $-208,697$ & & 225,854 & $-600,787$ & \\
\hline & $(100,843)$ & & $(136,865)$ & $(164,332)$ & & $(147,317)$ & $(470,227)$ & \\
\hline \multirow[t]{2}{*}{ PerformanceGoal_Efficiency } & $-36,794$ & $*$ & $86,375 *$ & $-91,283$ & $* * *$ & $-40,984$ & $-2,351$ & \\
\hline & $(19,084)$ & & $(44,769)$ & $(34,289)$ & & $(29,384)$ & $(27,334)$ & \\
\hline \multirow[t]{2}{*}{ Development_Feasibility } & $-428,778$ & ** & $-541,409$ & $-630,804$ & $*$ & $-384,678$ & $-580,409$ & $* *$ \\
\hline & $(194,671)$ & & $(656,394)$ & $(326,431)$ & & $(356,475)$ & $(231,362)$ & \\
\hline \multirow[t]{2}{*}{ Deployment_Feasibility } & 393,948 & $*$ & $-221,035$ & 485,950 & $* *$ & $-103,395$ & $1,807,000$ & $* * *$ \\
\hline & $(213,552)$ & & $(446,625)$ & $(198,591)$ & & $(260,165)$ & $(500,138)$ & \\
\hline \multirow[t]{2}{*}{ MarketGrowth_Potential } & $-77,299$ & ** & $-130,891$ & $-87,347$ & & $-17,947$ & 11,393 & \\
\hline & $(31,040)$ & & $(87,533)$ & $(120,589)$ & & $(48,304)$ & $(66,358)$ & \\
\hline \multirow[t]{2}{*}{ MarketGrowth_Robustness } & 20,582 & & $-112,664$ & 82,800 & & $-115,586 \quad * * *$ & 380,285 & $* * *$ \\
\hline & $(39,730)$ & & $(94,746)$ & $(77,769)$ & & $(40,932)$ & $(61,110)$ & \\
\hline \multirow[t]{2}{*}{ End Year } & 8,389 & & $-298,310$ & 141,124 & & 6,405 & 404,886 & \\
\hline & $(5,292)$ & & $(206,580)$ & $(213,797)$ & & $(7,363)$ & $(381,623)$ & \\
\hline \multirow[t]{2}{*}{ Constant } & $-13,320,000$ & & $604,100,000$ & $-279,200,000$ & & $-9,664,000$ & $-813,700,000$ & \\
\hline & $(10,610,000)$ & & $(415,800,000)$ & $(430,800,000)$ & & $(14,760,000)$ & $(768,000,000)$ & \\
\hline Observations & 207 & & 46 & 53 & & 91 & 17 & \\
\hline Number of programs & 7 & & 7 & 7 & & 7 & 6 & \\
\hline R-squared & 0.5303 & & 0.6999 & 0.7703 & & 0.0645 & 0.6533 & \\
\hline Wald Chi-squared & 22.77 & $* * *$ & $57.34 * * *$ & 26.33 & $* * *$ & $15.23 *$ & 47.97 & $* * *$ \\
\hline
\end{tabular}

Robust standard errors in parentheses, ${ }^{* * *} \mathrm{p}<0.01,{ }^{* *} \mathrm{p}<0.05,{ }^{*} \mathrm{p}<0$. 